\title{
O perfil dos alunos dos Ensinos Fundamental e Médio do Colégio de Aplicação da UFRGS
}

Karen Elisabete Rosa Nodari*

\section{Problema de pesquisa}

Conhecer o perfil dos alunos do Ensino Fundamental e Médio do Colégio de Aplicação da UFRGS.

\section{Justificativa}

Com a mudança do Colégio de Aplicação do Campus Central para o Campus do Vale em 1996, faz-se necessário conhecer a clientela do CAp/UFRGS para que as ações do ensino, desenvolvidas pela instituição, atinjam de forma mais efetiva a sua clientela.

\section{Objetivos}

Disponibilizar dados e resultados da pesquisa a diferentes áreas do conhecimento do CAp e da Universidade, com vistas à construção de novas ações de ensino, pesquisa e extensão e captação de recursos.

Conhecer as necessidades sociais dos alunos do CAp e de suas famílias, com vistas ao enfrentamento junto à rede de serviços, mediante o fomento de políticas sociais.

* Orientadora educacional do Colégio de Aplicação da Universidade Federal do Rio Grande do Sul (CAp-UFRGS). Doutora em Educação pela FACED-UFRGS. E-mail: karen.nodari@terra.com.br 
Ampliar o olhar da escola sobre o contexto familiar do aluno, contribuindo para compreendê-lo na sua totalidade.

\section{Metodologia}

Os dados serão analisados mediante testes paramétricos e não-paramétricos. Opta-se pela corrente pós-crítica em Educação para orientar o processo de análise e interpretação dos dados.

\section{Resultados esperados e impactos}

Espera-se confirmar o elevado percentual de alunos do Colégio provenientes do município de Viamão.

\section{Referências básicas}

DEMO, Pedro. Metodologia do conhecimento científico. São Paulo: Atlas, 2008.

GIL, Antonio Carlos. Métodos e técnicas de pesquisa social. 6 ed. São Paulo: Atlas, 2008.

MARSIGLIA, R. M. G. (Docente). Orientações básicas para a pesquisa. In: Serviço Social e Saúde: formação e trabalho profissional. São Paulo: Cortez Editora, 2006.

STUMPF, Maria Conceição T. Quem são os alunos do Aplicação? Cadernos do Aplicação. Porto Alegre: v. 8, n. 2, p. 131-144, jul/dez. 1995.

UNIVERSIDADE FEDERAL DO RIO GRANDE DO SUL. Perfil $e$ representações dos estudantes do Colégio de Aplicação da Universidade Federal do Rio Grande do Sul: Relatório Final. Porto Alegre: 2003.

UNIVERSIDADE FEDERAL DO RIO GRANDE DO SUL. Sobre $o$ CAp. Disponível em: $<\mathrm{http}: / / w w w . c a p . u f r g s . b r /$ interno.php $>$. Acesso em: 22 mar. 2010. 